\title{
Formação profissional e prática docente: representações sociais de professores da rede básica de ensino
}

\author{
Professional training and teaching practice: social \\ representations of teachers in the basic education
}

network

\author{
Formación Profesional y Práctica Docente: \\ representaciones sociales de los profesores de la red \\ pública básica de enseñanza
}

\author{
IVANY PINTO NASCIMENTO ${ }^{\mathrm{a}(\mathbb{D})}$ \\ PATRÍ́CIA RODRIGUES DE OLIVEIRA KIMURA ${ }^{\mathrm{b}}$ (id \\ MAURA LÚCIA MARTINS CARDOSO ${ }^{c}$ iD
}

\section{Resumo}

Este artigo tem como objetivo apresentar os resultados de um estudo que trata das representações sociais de professores sobre a inter-relação entre formação profissional e prática pedagógica docente. Os dados analisados incidem sobre a dimensão "Formação e prática docente: Processo ensino aprendizagem", que corresponde ao recorte de uma pesquisa guardachuva ${ }^{1}$, intitulada: "Os fatores que determinam a permanência na docência e as implicações no trabalho e nos desafios da contemporaneidade", de abordagem qualitativa, do tipo descritivaanalítica, que compõe um estudo desenvolvido com os professores da rede pública estadual de ensino da cidade de Belém, no estado do Pará. Os instrumentos utilizados para a coleta dos dados foram o questionário e a entrevista semiestruturados, aplicados a oitenta e dois

\footnotetext{
${ }^{1}$ Conforme Nascimento e Rodrigues (2018), a pesquisa guarda-chuva consiste em uma pesquisa mais abrangente que envolve várias dimensões.

a Universidade Federal do Pará (UFPA), Belém, Pará, Brasil. Doutora em Educação, email: ivany.pinto@gmail.com

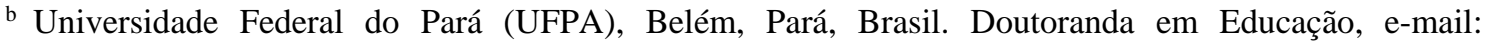
patyrok@gmail.com

c Universidade Federal do Pará (UFPA), Belém, Pará, Brasil. Doutoranda em Educação, e-mail: mauraemlc@gmail.com
} 
professores que atuam em turmas do Ensino Médio. O tratamento e sistematização das informações ocorreu por meio da técnica de análise temática, procedendo-se as análises com base nos pressupostos teóricos da teoria das representações sociais (TRS), na perspectiva da abordagem processual de Serge Moscovici (1978). Os resultados destacam os seguintes aspectos: "Formação, experiência e prática docente" e "Aprimoramento teórico e prático continuado". Esses aspectos centralizam as imagens-objetivações e os sentidos-ancoragens atribuídos pelos professores participantes da pesquisa. Dentre as principais implicações decorrentes destas representações, é reafirmada a necessidade de reestruturação dos modelos formativos, como um aspecto essencial ao aprimoramento da prática pedagógica dos professores e ao desenvolvimento da profissão.

Palavras-chave: Representações sociais. Formação profissional. Prática pedagógica. Aprimoramento.

\section{Abstract}

This article aims to present the results of a study that deals with the social representations of teachers on the interrelationship between professional training and teaching pedagogical practice. The analyzed data focus on the dimension "Teacher training and practice: the teaching-learning process", which corresponds to the clipping of an umbrella survey, entitled: "The factors that determine the permanence in teaching and the implications for work and contemporary challenges ", with a qualitative approach, of the descriptive-analytical type, which composes a study developed with teachers from the state public school system in the city of Belém, in the state of Pará. The instruments used for data collection were the questionnaire and the semi-structured interview, applied to eighty-two teachers who work in high school classes. The treatment and systematization of information occurred through the technique of thematic analysis, proceeding the analyzes based on the theoretical assumptions of the theory of social representations (TRS), in the perspective of the procedural approach of Serge Moscovici (1978). The results highlight the following aspects: "Training, experience and teaching practice" and "Continued theoretical and practical improvement". These aspects centralize the images-objectifications and the meanings-anchors attributed by the teachers participating in the research. Among the main implications arising from these representations, the need to restructure the training models is reaffirmed, as an essential aspect to improve the pedagogical practice of teachers and the development of the profession

Keywords: Social representations. Professional qualification. Pedagogical practice. Enhancement.

\section{Resumen}

Este artículo tiene como objetivo presentar los resultados de un estudio que se trata de las representaciones sociales de profesores sobre la interrelación entre formación profesional y práctica pedagógica docente. Los datos analizados inciden acerca de la dimensión "Formación y práctica docente: Proceso de enseñanza y aprendizaje", que corresponde al recorte de una pesquisa integrada, intitulada "Los factores que determinan la permanencia en la docencia y las implicaciones en el trabajo y en los desafios de la contemporaneidad", de abordaje cualitativa, de modelo descriptivo-analítico, que compone un estudio desarrollado con los profesores de la red pública estadual de enseñanza de la ciudad de Belém, en el Estado de Pará. Los instrumentos utilizados para la colecta de los datos fueron el cuestionario y la entrevista semiestructurados, aplicados a ochenta y dos profesores que actúan en clases de enseñanza secundaria. El tratamiento y sistematización de las informaciones ocurrió por medio 
de la técnica de análisis temática, análisis que procedió con base en los presupuestos teóricos de la teoría de las representaciones sociales (TRS), en la perspectiva del abordaje procesual de Serge Moscovici (1978). Los resultados destacan los siguientes aspectos: "Formación, experiencia y práctica docente" y "Perfeccionamiento teórico y práctico continuado". Estos aspectos centralizan las imágenes-objetivaciones y los sentidos-ancorajes atribuidos por los profesores participantes de la pesquisa. Entre las principales implicaciones derivadas de estas representaciones, se reafirma la necesidad de reestructuración de los modelos formativos, como un aspecto esencial al perfeccionamiento de la práctica pedagógica de los profesores y al desarrollo de la profesión.

Palabras clave: Representaciones sociales. Formación profesional. Práctica pedagógica. Perfeccionamiento.

\section{Introdução}

Este artigo objetiva apresentar os resultados da pesquisa realizada com professores da rede pública estadual de Educação Básica do município de Belém, capital do estado do Pará. O estudo parte da análise das Representações Sociais (RS) desses sujeitos sobre a inter-relação entre formação profissional e prática pedagógica docente. Segundo os dados disponibilizados pelo Educacenso (INEP, 2019), a rede pública estadual de ensino, na cidade de Belém, atendia em 2019 um número aproximado de 600 mil estudantes, distribuídos em 963 escolas. A pesquisa foi desenvolvida em oito escolas públicas estaduais de Ensino Fundamental e Médio, situadas em bairros centrais e periféricos da cidade de Belém. Para este escrito, destacamos a dimensão de análise: Formação e prática docente: Processo ensino aprendizagem que integrou o estudo que denominamos de guarda-chuva, intitulado: Os Fatores que Determinam a Permanência na Docência e as Implicações no Trabalho e nos Desafios da Contemporaneidade.

Pensar em prática pedagógica docente é propor-se a reflexão sobre um saber fazer próprio, que orienta a ação educativa e é mobilizado pelo professor durante o processo de ensino e aprendizagem. Sob este enfoque, ela se constitui a partir de sentidos e significados que expressam uma intencionalidade objetiva, voltada a construção de estratégias, técnicas e ferramentas potenciais para a produção do conhecimento.

No entanto, essa construção não ocorre deslocada de seu tempo e espaço. Como prática social, a educação é um processo cultural e político, situado em um determinado contexto, logo, significa dizer que “[...] os fenômenos educativos, por 
sua natureza social se tornam também históricos" (GAMBOA, 2012, p. 67). Desse modo, a prática pedagógica docente como componente da ação educativa, situa-se em um contexto específico, constituindo um saber prático que, teoricamente fundamentado, converte-se em ações direcionadas ao ensino.

Sob essa lógica, compreendemos a prática pedagógica docente como processo que se constitui dialeticamente, na confluência das dimensões profissional e pessoal do ser professor, considerando as experiências objetivas e subjetivas que perpassam o processo de formação contínua e o exercício permanente da profissão.

Segundo Tardif (2000, p. 10), o conhecimento mobilizado pelos profissionais para desempenhar suas atividades de trabalho compõe um sistema de ação pelo qual a realidade social e individual é constituída e o define como uma “[...] epistemologia da prática profissional o estudo do conjunto dos saberes utilizados realmente pelos profissionais em seu espaço de trabalho cotidiano para desempenhar todas as suas tarefas".

Sob este ângulo, a noção de saber recebe um sentido amplo que compreende os conhecimentos, as competências, as habilidades ou aptidões, bem como, as atitudes, aspectos que, em muitos casos, destaca o autor, são denominados de “saber, saber-fazer e saber ser". Este sentido amplo, via de regra, reflete o que os profissionais mencionam em relação aos seus próprios saberes profissionais. Para Tardif (2000, p. 11):

\begin{abstract}
A finalidade de uma epistemologia da prática profissional é revelar esses saberes, compreender como são integrados concretamente nas tarefas dos profissionais e como estes os incorporam, produzem, utilizam, aplicam e transformam em função dos limites e dos recursos inerentes às suas atividades de trabalho. Ela também visa a compreender a natureza desses saberes, assim como o papel que desempenham tanto no processo de trabalho docente quanto em relação à identidade profissional dos professores.
\end{abstract}

Como um conhecimento, voltado a natureza do trabalho e a realização de atividades e tarefas a ele relacionadas, obviamente, este é atravessado pelos contextos reais e locais provenientes de onde se inserem e atuam esses profissionais, o que significa dizer que essa prática é afetada por fatores externos. 
Nesse sentido, há de se considerar que no exercício do ofício, os professores estão expostos a situações que impactam em sua prática profissional. Trata-se de condicionantes que interferem em suas realidades e que passam a compor o núcleo simbólico e figurativo de suas percepções e representações sobre o trabalho que realizam. Assim, os estudos relacionados à profissão docente precisam levar em consideração aspectos e fatores que tomam parte da realidade laboral desses sujeitos e que têm implicações diretas sobre sua prática.

Nas últimas décadas, os estudos produzidos sobre o tema da profissão docente se voltam à análise de diferentes aspectos relacionados a esta, que abordam desde as dificuldades para a consolidação de um estatuto profissional, perpassando por questões como a ressignificação do trabalho, face às novas realidades e demandas sociais e pelos desafios do ofício que, por sua vez, segundo Neves e Nascimento (2013, p. 8773) são redimensionados em face de uma conjuntura de

[...] transformações sociais que colocam em questionamento o papel da educação escolar e por consequência o papel do próprio professor [...] A ideia central é que as dificuldades envolvem o professor numa série de exigências como desenvolvimento de competências, avaliação por desempenho cognitivo, conhecimento de novas tecnologias, elevação do nível de escolaridade, levando-lhes a um mal-estar representado por sentimentos conflitivos em relação à própria profissão.

Para essas autoras, as condições adversas que circundam o trabalho docente têm implicações nas representações construídas pela categoria, acerca da profissão e da própria identidade. Em conformidade com as ponderações em destaque, Gomes (2002, p. 4) acrescenta que,

\footnotetext{
Quando tratamos de sujeitos sociais que partilham espaços, tempos e representações sociais na/sobre a escola, não podemos deixar de considerar que o contexto mais amplo em que cada um dos sujeitos está inserido interfere profundamente em suas expectativas e percepções.
}

A partir desses pressupostos, é necessário considerar que as adversidades e as incertezas em que se encontra exposta a categoria docente, subjugada, sobretudo, por contextos de precarização profissional, implica em questões, como: desvalorização salarial e social do trabalho docente, com consequente diminuição de 
sua autonomia e de seu status social. Essa situação repercute, inclusive, na relativização e esvaziamento de seus conhecimentos técnicos e instrumentais, levando a constantes ataques por parte de outros grupos ou instâncias sociais, que colocam em questão a própria competência profissional desses trabalhadores.

A esse estado de coisas agrega-se o processo de reconfiguração dos espaços e modos de aprender e produzir conhecimento, profundamente impactados pelo progresso tecnológico e informacional e pela maximização das demandas educacionais que cada vez mais "[...] requer das professoras e professores conhecimentos e competências especializadas adquiridos e mantidos através de estudo rigoroso" (DELORS, 1998, p.46).

No elenco das questões que atingem de forma negativa a profissão, podemos destacar ainda a violência física e simbólica, presentes em muitas instituições escolares, bem como, os processos de regulação e desregulação da profissão docente que atua, dentre outros aspectos, em uma lógica perversa de mercantilização da educação que, evidentemente, não passaria incólume aos efeitos colaterais produzidos pelo fenômeno da globalização, que estabeleceu "[...] um mundo sem fronteiras, de livre circulação de dinheiro, mercadorias, ideias, da interpenetração das culturas [...]" (FIDALGO; MACHADO, 2000, p. 178), interferindo, de maneira singular, nas relações de produção e trabalho, em todos os níveis.

Não obstante essa conjuntura, grandes são as expectativas atribuídas ao papel do professor, especialmente no que se refere ao desenvolvimento e sucesso de seus alunos, bem como no que tange a responsabilização por aquilo que ocorre na escola e os desdobramentos que estas situações apresentam. Ao elaborar reflexões sobre as condições atuais em que se encontram os professores, Monteiro (2015, p. 134) aponta que:

A escola e a profissão docente são vítimas, ainda, de um excesso de expectativas [...] "São habitualmente chamados a resolver os problemas pessoais, sociais e políticos que a família e outras instituições ou não querem ou não podem resolver" [...]a sociedade parece esperar da escola que ela remedeie todos os seus males e que, sozinha, dê à juventude essa formação e essa educação que nenhuma outra instituição consegue dar-lhe. 
Chama a atenção, nesse enunciado, que aos professores se atribui grandes demandas, as quais inclusive, em muitos casos, não estão sob o seu controle. Esse fluxo de atribuições e cobranças excessivas, associadas a um contexto de incertezas, precarização e desvalorização do trabalho docente tem sido responsável por uma série de questões que impactam negativamente a profissão, como: queda gradativa da procura pelo ingresso em cursos de licenciaturas, o desencanto e o consequente abandono da profissão e o adoecimento docente, dentre outras.

Especificamente, sobre os impactos relacionados à atratividade da carreira docente, cumpre observar que, historicamente, a profissão lidou com condicionantes que cada vez mais têm implicado na redução do interesse das novas gerações em exercê-la, os quais parecem ainda distantes de serem superados. Acerca desses aspectos, recorremos a Anderson² (2004) apud Monteiro (2015), que nos traz elementos que podem explicar esse fenômeno. Segundo Monteiro (2015, p. 135136):

[...] a deterioração das condições de trabalho e os baixos salários estão a desencorajar as pessoas de ingressar na profissão docente" (ANDERSON, 2004, p.19), e muitas abandonam mesmo a profissão [...] há na profissão um sentimento geral de mal-estar e desmotivação que não contribui para a atratividade da profissão (p.18, 82-83). Muitas professoras e professores têm vergonha de dizer que o são e não recomendam a profissão.

Diante dessas questões, não surpreende que o desinteresse pela profissão docente por parte dos estudantes que ingressarão no Ensino Superior constitua um fenômeno crescente, cujos impactos já se fazem sentir. Monteiro (2015, p. 136) resume temerosamente "[...] A profissão docente é cada vez mais complexa, difícil, exigente, exercida em condições adversas, e sem elevada profissionalidade”.

No tocante a esse aspecto, estudos publicados em revistas científicas e pesquisas realizadas por órgãos ligados a educação no país revelam um panorama preocupante, que se instala como entrave à formação de um quadro profissional qualificado para o magistério.

\footnotetext{
2 ANDERSON, L. W. Increasing teacher effectiveness. Paris: UNESCO, International Institute for Educational Planning, 2004. Disponível em: <http://unedosc.unesco.org/images/0013/001376/137629e.pdf>. Acesso em: 23 jan. 2010.
} 
Um estudo estatístico realizado pelo MEC em 2018 apontou que a média de evasão para os cursos de Ensino Superior ficou em torno de 15\%, entretanto, constatou-se que as licenciaturas, cursos voltados à formação de professores, apresentam, em geral, desempenho abaixo da média e são os que mais perdem alunos, se comparado a outros cursos. Um exemplo que ilustra essa situação foi a taxa de 25\% de evasão, registrada no curso de licenciatura em Matemática, neste mesmo ano (INEP, 2019).

O Censo do Ensino Superior de 2019 indica que esse prognóstico se mantém, como revelam os dados abaixo, disponibilizados no site do INEP (2019, p. 14):

Hoje 1.589.440 alunos frequentam cursos de licenciatura no Brasil, o que representa 19,3\% do total de alunos na educação superior de graduação. Em 2017, a matrícula na modalidade a distância manteve sua tendência de crescimento, enquanto a modalidade presencial tem praticamente o mesmo número de alunos de 10 anos atrás [...] A menor procura pelos cursos de licenciatura tem impacto direto na educação básica, pois faltam professores.

Esses números revelam que o estigma que acompanha a profissão docente desde a sua institucionalização e que, em grande medida, é resultante dos desafios relacionados a carreira, o que impacta de modo negativo o status da profissão e passa a compor as imagens e os sentidos que os grupos sociais partilham sobre ela. Em síntese, essas representações repercutem objetivamente nos discursos, posturas e práticas dos sujeitos que, por diferentes ângulos, não verão a carreira do magistério com boas expectativas.

Como principal reflexo dessa conjuntura, têm-se acentuado o processo de precarização e desvalorização da profissão. $\mathrm{O}$ que permite inferir que a correlação desses fatores engendra um panorama de contradições que impacta significativamente a realidade objetiva desses profissionais na contemporaneidade, ampliando os desafios que atravessam o horizonte da profissão.

\section{Formação profissional e prática pedagógica docente}

Como dimensão que se constitui no exercício da profissão e, portanto, também no processo de formação e autoformação contínua, a prática pedagógica 
docente implica na mobilização de um repertório de conhecimentos profissionais específicos, que devem ser aplicados com base nos fundamentos epistemológicos que orientam a profissão. Nessa perspectiva, Gatti (2013, p. 54) destaca que:

[...] os profissionais da educação constroem suas práticas educativas em suas formações diversas e em seu exercício docente. Práticas educativas significativas se ancoram em: domínio de conhecimentos: quer em áreas de especialidade, quer de natureza pedagógica; sensibilidade cognitiva: capacidade ampliada pela visão dos conhecimentos em seus sentidos lógicos e sociais, em seus contextos, aliados à compreensão das situações de aprendizagem e dos que irão aprender.

Desse modo, a formação, em uma área específica do conhecimento, pressupõe o primeiro nível institucional no âmbito da profissionalização que, sobretudo, não é estanque, isto é, não se esgota em si mesma, ao contrário, precisará de modo permanente ser revisitada.

Esse movimento de retomada remete ao desejo e, para além disso, à necessidade de aprimoramento que, no caso da profissão docente, torna-se praticamente um imperativo, diante das intensas transformações que os novos contextos sociais imprimem às práticas humanas, especialmente, em decorrência dos avanços tecnológicos e informacionais, em grande medida, responsáveis por reconfigurar as dinâmicas e as lógicas de aprendizagem. Essas transformações consolidaram o conceito de sociedade do conhecimento, cuja principal premissa, segundo Wille e Ferreira (2014, p. 599), é que:

A valorização destas sociedades atuais relaciona-se com o nível de formação dos seus cidadãos, bem como das capacidades de atualização, mudança e alteração. Mas, esses mesmos conhecimentos atualmente têm datas limitadas, como um período de validade, deixando-nos alertas para que como cidadãos e profissionais possamos estar sempre atualizando nossas competências.

Em busca do aprofundamento de conhecimentos teóricos e práticos que melhor possam subsidiar o desenvolvimento de práticas que possibilitem a atuação de maneira dialógica e coerente com as questões que atravessam a dinâmica da sala de aula, bem como o cotidiano das escolas, os professores seguem em contínuo movimento de formação e autoformação.

Isso implica um movimento de inovação com os processos de formação profissional e, ao mesmo tempo, reafirmação da dimensão política, no sentido da 
ação intencional e direcionada, isto é, comprometida com a garantia da legitimidade do papel do professor, como condutor e gestor consciente de suas ações e práticas e detentor de um saber próprio que caracteriza e define sua profissão.

Nesse sentido, recorremos aos conceitos de profissionalidade, profissionalismo e profissionalização (GATTI, 2013; MONTEIRO, 2015; PAULA JÚNIOR, 2012; RAMALHO; NUÑEZ; GAUTHIER, 2003; TARDIF, 2000), como categorias conceituais relevantes ao processo de aprimoramento e qualificação laboral e ao desenvolvimento de ações e políticas de fortalecimento da profissão, ressaltando como elas se encontram intimamente relacionadas ao processo de formação permanente.

Conforme Paula Júnior (2012, p. 4-5, grifos nossos):

Profissionalidade é o aperfeiçoamento docente na busca de um desenvolvimento profissional e pessoal. A própria formação continuada ou a busca por ela. A ânsia que o professor tem por conhecer, por crescer, aumentar seu conhecimento, aperfeiçoar-se e ser reconhecido por isso entre os pares e na sociedade. É um movimento de dentro para fora, é uma busca, uma procura porque depende do movimento do professor em busca de algo [...] Por sua vez, Profissionalismo é este "compromisso do professor" com o projeto pedagógico da escola e com o ato de ensinar que ultrapassa os limites da sala de aula [...]a Profissionalização, para os professores, corresponde ao seu status quo, sua posição na sociedade, a partir das políticas públicas a eles direcionadas [...] a profissionalização no magistério está ligada diretamente às políticas públicas educacionais, ao contexto histórico vigente, e a valorização da profissão docente pelas políticas sociais.

Essas categorias carregam princípios essenciais para a consolidação de um estatuto profissional que possibilite elevar o conceito da profissão. Por certo, não se pode perder de vista que se trata de ações articuladas, não restritas, exclusivamente, a iniciativa dos professores, porém, devemos reconhecer que essa disposição dos profissionais ao processo de mudança é indispensável. A disposição de mudança e o engajamento é um dos elementos que culminará na criação de estratégias que obriguem os demais setores envolvidos (governo, associações trabalhistas, sociedade organizada) a execução de ações que efetivamente possam mudar a situação da profissão docente na atualidade.

Desse modo, propomos a análise de como os professores se movimentam nesse cenário de aprofundamento dos problemas que se relacionam a sua profissão 
e como percebem o desenvolvimento de suas práticas, a partir de suas trajetórias formativas.

Nessa perspectiva, a discussão sobre o tema da formação profissional e seus impactos na prática docente, para além de nos possibilitar a análise e a reflexão sobre questões pertinentes à reelaboração dos princípios que devem nortear as matrizes epistemológicas deste saber fazer, próprio do ofício de ensinar, nos fornece indícios de como contribuir para a implementação das mudanças necessárias nos processos de formação de professores, dos quais tomamos parte.

Por esse prisma, as percepções dos professores sobre a formação profissional e a prática docente, como elementos que se articulam no processo de construção de um conhecimento próprio e específico do trabalho que realizam, configura relevante objeto de investigação no campo das ciências da educação e, especificamente, no âmbito das discussões sobre formação de professores. Isto porque, essa perspectiva de análise, ao tempo que nos permite identificar os elementos constituintes das representações sociais, presentes nos discursos e práticas que norteiam a ação docente em um dado contexto, possibilita a esses sujeitos problematizarem e questionarem sobre os princípios ideativos e os conhecimentos práticos que orientam suas ações em busca de "[...] uma epistemologia da prática que se mostre, de fato, pertinente" (TARDIF, 2000, p. 10).

Para além dessas questões, aponta para as expectativas e desejos que estes profissionais nutrem sobre o próprio trabalho, aspecto intimamente relacionado à decisão por investir e permanecer na carreira, dado que, de acordo com Arruda (2002, p. 66-67):

Se no plano do sujeito se inclui o imaginário, as emoções o desejo como afirma Figueira apud Mendes, as representações sociais são um de seus componentes. Em uma sociedade cujo fluxo de informações é incessante, é de se supor que as representações de hoje não sejam as mesmas de ontem, nem de amanhã. As representações sociais possuem dinâmica própria e inclui mudança na sua substância mesma (ABRIC, 1994³, ROUQUETTE, 19944). Elas acompanham, desta forma, o caráter contingente das subjetividades.

\footnotetext{
${ }^{3}$ ABRIC, J. C. (org.). Pratiques sociales et représentations. Paris: Presses Universitaires de France, 1994.

${ }^{4}$ ROUQUETE, M. L. Sur la connassance des masser. Essai de Psychologie politique. Grenoble: Presses Universitaires de Grenoble, 1994.
} 
Dessa feita, pretendemos analisar esse tema, a fim de contribuir para o aprofundamento do debate e a expansão do campo do conhecimento sobre as representações sociais acerca do processo de formação profissional contínua e suas repercussões na prática pedagógica de professores, no âmbito do trabalho e da formação docente na Amazônia, região na qual nos inserimos na condição de professoras e pesquisadoras.

\section{Procedimentos teórico-metodológicos}

O presente estudo foi desenvolvido a partir de uma abordagem qualitativa de cunho explicativo e analítico, visto que identificamos uma melhor adequação desse tipo de abordagem para o processo de investigação de fenômenos complexos de natureza social e cultural.

Para apreender as representações sociais dos professores sobre a interrelação entre formação profissional e prática pedagógica docente, tomamos por base a perspectiva psicossocial, proposta por Serge Moscovici (1978) e aprofundada por sua principal colaboradora, Denise Jodelet (2001), associada à análise temática proposta por Braun e Clarke (2016), como técnica utilizada para o tratamento e análise das narrativas emitidas pelos professores.

Enquanto aporte teórico e metodológico, a Teoria das Representações Sociais (TRS) viabiliza o mapeamento dos sentidos e significados atribuídos pelos sujeitos ou grupos sociais a determinados objetos, fenômenos, eventos ou acontecimentos. Nas palavras de Moscovici (1978, p. 123): “[...] uma representação social pode ser definida como um sistema de valores, ideias e práticas”. Esse sistema estabelece um ordenamento que permite às pessoas uma orientação sobre a dinâmica do mundo material e social e o auxílio ao desenvolvimento de mecanismos de controle sobre ele.

Desse modo, o presente estudo pauta-se pela análise, interpretação e compreensão das ideias, concepções, valores e práticas cotidianas que se naturalizam 
e atravessam a dinâmica das relações instituídas por professores e professoras no decorrer de suas práticas profissionais.

Participaram da pesquisa oitenta e dois professores da rede pública estadual de ensino de Belém. Esses professores encontram-se vinculados a oito escolas de Ensino Fundamental e Médio da região. Esclarecemos que, apesar da concessão de autorização desses sujeitos para o uso das informações levantadas, por meio da assinatura do Termo de Consentimento Livre Esclarecido (TCLE), suas identidades foram mantidas em sigilo. Para referendar as falas desses sujeitos, foi criado um código identificador, em que se fez uso da consoante P, inicial da palavra professor, acompanhada do número correspondente, atribuído a cada um dos oitenta e dois participantes da pesquisa.

Por meio da análise do material coletado, estruturamos as representações sociais dos professores entrevistados em duas categorias temáticas, são elas: "Formação, experiência e prática docente" e "Aprimoramento teórico e prático continuado”. A partir dessas categorias, desenvolvemos a análise para identificar as imagens-objetivações e os sentidos-ancoragens que estruturam as representações sociais elaboradas por professores da rede pública estadual do município de Belém, sobre a inter-relação entre formação profissional e prática pedagógica docente.

\section{Instrumentos da pesquisa e levantamento dos dados}

Para o levantamento dos dados, utilizamos o questionário semiestruturado que, conforme destaca Severino (2007, p. 125), é um recurso fundamental ao processo de caracterização e construção do perfil dos sujeitos pesquisados, bem como possibilita a obtenção de respostas para questões específicas de interesse do pesquisador. Para aprofundar algumas questões, empregamos a entrevista semiestruturada que, de acordo com Triviños (1987, p. 152): “[...] favorece não só a descrição dos fenômenos sociais, mas também sua explicação e a compreensão de sua totalidade". Segundo este autor, o uso da entrevista pressupõe a participação 
ativa e consciente do interlocutor/pesquisador durante todo o processo de coleta das informações.

Os questionários foram aplicados em um período de 45 dias (um mês e meio) durante os intervalos das aulas e as entrevistas ocorriam em seguida a devolução dos questionários. A coleta do material mobilizou oito esquipes de trabalho, constituídas por dois a três pesquisadores, em média. Destacamos que esses encontros ocorreram na sala de professores das respectivas escolas, onde esses profissionais trabalhavam, nos momentos em que eles se encontravam disponíveis para respondêlos. Durante a aplicação, os pesquisadores explicaram os objetivos da pesquisa e as questões contidas no instrumento, acompanhando o processo de preenchimento deste e esclarecendo as dúvidas apresentadas por seus interlocutores.

\section{Procedimentos de análise e interpretação dos dados}

Para o desenvolvimento da pesquisa que fundamentou a escrita deste artigo, tomamos por referência o aporte teórico e metodológico da Teoria das Representações Sociais (TRS) de Serge Moscovici (1978) e Denise Jodelet (2001), em correlação com as temáticas formação profissional e prática pedagógica docente. A técnica de análise temática, proposta por Braun e Clarke (2016), subsidiou o tratamento e sistematização dos dados.

Para identificarmos as representações sociais do grupo pesquisado sobre o tema de investigação, a partir dos pressupostos da TRS, recorremos aos processos de objetivação e ancoragem, que são fundantes na estruturação das representações, elaboradas e partilhadas pelos grupos sociais.

Segundo Moscovici (1978), o processo de objetivação consiste na transformação de noções em conhecimentos esquematizados. Trata-se da combinação de esquemas ou combinação de elementos. É a união de um conceito a uma imagem, que irá tornar tangível e concreto aquilo que foi representado, mas que ainda se encontra em um plano abstrato. Diz respeito a passagem de conceitos 
ou ideias para esquemas simbólicos ou imagens concretas, transportando-os para o domínio do real.

Já o processo de ancoragem é a integração de novos conhecimentos a conceitos já existentes e pode ser considerado como uma espécie de rede de significações que circundam o objeto e o relacionam a valores e práticas sociais já consolidadas, tendo por principal finalidade classificá-lo e agrupá-lo a uma categoria específica já conhecida, inserindo-o a um pensamento já constituído.

Para o tratamento e sistematização dos dados, utilizamos a técnica de análise temática. Trata-se de uma técnica que tem aspectos semelhantes aos procedimentos aplicados na análise qualitativa, dentre eles a busca por padrões, a recursividade, a flexibilidade, a homogeneidade interna nas categorias/temas e heterogeneidade externa entre as categorias/temas que estão presentes nas análises de abordagem qualitativa. Sua aplicação consiste na organização dos dados por agrupamentos, que são sistematizados em unidades de sentidos, seguida pela elaboração das respectivas temáticas de agrupamentos, possibilitando identificar os pontos de convergência e consenso entre os sujeitos entrevistados (BRAUN; CLARKE, 2016).

Com base nas orientações teórico metodológicas que fundamentam este estudo, executamos as seguintes etapas: 1) Digitamos e revisamos os dados levantados, para compor um banco de dados; 2) Geramos os códigos que subsidiaram o agrupamento dos dados; 3) Elaboramos as unidades temáticas; 4) Geramos o mapa temático de análise; 5) Procedemos a definição e a nomeação dos temas; 6) Produzimos os relatos científicos de análise.

\section{Discussão dos dados: as representações sociais de professores da rede pública estadual de ensino de Belém-PA, sobre a inter-relação entre formação profissional e prática docente}

Desenvolvemos as análises, a partir de duas temáticas analíticas, a primeira intitulada "Formação, experiência e prática docente" e a segunda "Aprimoramento teórico e prático contínuo", estas que assumem centralidade nos discursos dos 
sujeitos pesquisados e orientam o processo de apreensão das objetivações e ancoragens, constitutivas das representações sociais que esses sujeitos elaboram sobre a inter-relação entre formação profissional e prática docente.

Desse modo, os princípios que norteiam a análise das narrativas dos sujeitos pesquisados fundamentam-se nos questionamentos propostos por Jodelet (2001), os quais são basilares para conduzir as investigações e análises sobre representações sociais. São eles: quem sabe e de onde sabe? O que e como sabe? Sobre o que sabe e com que efeitos?

No contexto deste estudo: quem sabe e de onde sabe?

Os sujeitos que participaram desta pesquisa são oitenta e dois professores, vinculados à rede estadual de ensino público do município de Belém, capital do estado do Pará, que atuam em turmas do $1^{\circ}$ ao $3^{\circ}$ ano do Ensino Médio. Esses docentes ministram os diferentes componentes curriculares que integram esse nível de ensino e estão distribuídos em oito escolas, situadas em bairros centrais e periféricos do município de Belém.

Sobre o que sabem e com que efeitos?

\section{Formação, experiência e prática docente}

A Formação, experiência e prática docente comparece nas narrativas destes professores, articulada ao sentido de construção de um saber específico que caracteriza o trabalho docente, bem como com a construção de uma identidade profissional, isto é, como um fator determinante tanto para o desenvolvimento de um repertório de conhecimentos que lhes dá suporte para desempenhar suas funções adequadamente, quanto para a configuração da imagem e do sentido de pertencimento a uma categoria profissional.

Ao discorrerem sobre os impactos e a influência que a formação profissional, em nível de Graduação, exerceu sobre suas práticas, 61,5\% dos entrevistados referendaram a sua importância para a construção dos conhecimentos relativos a área em que atuam, atribuindo destaque à excelência dos professores que tiveram, 
porquanto foram inspiradores, servindo-lhes como modelos a serem seguidos. Essas percepções encontram eco no relato do P:01“"...] eu tive a oportunidade de ter tido excelentes professores, nos quais me espelhei e que me inspiraram no sentido de promover a reflexão e interesse dos alunos pelo seu aprendizado." Monteiro (2016), ao discorrer sobre profissionalidade e autorregulação do trabalho docente, destaca a influência em potencial que os professores podem ter sobre seus alunos, no percurso do processo de formação. Sobre isto, assim o diz: “[...] Há uma crônica inconsciência da silenciosa, mas profunda ressonância que as professoras e professores têm na vida das crianças, adolescentes e jovens” (MONTEIRO, 2015, p. 150)

Conforme argumenta esse autor, a base do conhecimento da profissão docente deve, por um lado, incluir os saberes relativos ao ato de ensinar, os métodos e as estratégias de ensino, a gestão da sala de aula (disciplina), a capacidade de cooperação e colaboração, o foco no desenvolvimento profissional contínuo; e por outro, associá-los a um conjunto de características que dizem respeito a qualidades que a profissão requer e que estão na ordem “[...] do afetivo, do moral, do intelectual, da amabilidade, da serenidade, da relacionalidade, do acolhimento da alteridade e da abertura à diversidade, de rigor e utopia” (MONTEIRO, 2015, p. 152), que devem ser consideradas como requisitos necessários à profissão e estimuladas no processo de preparação para o exercício da docência.

Estas são, por certo, características desejáveis e necessárias a boa condução de um trabalho e que devem integrar os princípios deontológicos que regem a profissão, todavia, no caso do ofício de professores é ainda de extrema importância garantir as condições mínimas necessárias, para que o processo de aprendizagem seja, de fato, mais promissor.

No tocante a este aspecto, Monteiro (2015) adverte que, sob a égide do conteúdo normativo pertinente ao direito à educação, a qualidade da educação é um conceito de dimensões complexas que, ao se articularem, concorrem para a conformação de uma atmosfera favorável ao estímulo e desenvolvimento das aprendizagens. Nesse contexto, se inclui a dimensão material que trata da "[...] disponibilidade (tanto física como econômica), a acessibilidade e o equipamento de 
estabelecimentos de educação seguros e saudáveis; os meios financeiros e humanos, os recursos de ensino/aprendizagem; remuneração dos profissionais da educação etc." (MONTEIRO, 2015, p. 164).

Outro aspecto, destacado como positivo na percepção desse grupo de entrevistados, diz respeito a qualidade da formação acadêmica e científica que esses profissionais relatam terem recebido em seus cursos de Graduação. Conforme os discursos analisados, essa formação lhes permitiu forjar conhecimentos que, posteriormente, foram aprofundados e consolidados por meio do encontro com a realidade das salas de aula e das instituições de ensino em que se inseriram. Assim, eles consideram que os conhecimentos construídos, durante o processo de formação, consolidaram-se, de fato, por intermédio da articulação com as experiências vivenciadas no exercício da profissão, conforme expressa o P:57: “[...] considero que tive uma boa formação em história, mas existiram desafios relacionados a como proceder em algumas situações. Isso o curso não me deu muito, fui aprendendo no dia a dia".

Destacamos na partilha dessas ideias, a compreensão de que há um processo de retroalimentação entre a teoria e a prática que, no curso das aprendizagens, constituem-se em dimensões de um mesmo saber, logo, devem estar intimamente integrados. No tocante a essa percepção, Gatti (2013, p. 54) adverte: “[...] Práticas educacionais são processos da maior importância, têm seus fundamentos teóricos e associam-se a uma filosofia educacional. Práticas geram teorizações e teorizações geram práticas, em movimento recursivo".

As proposições de Gatti (2013) são complementadas pelas observações de Tardif (2000, p. 54) ao refletir sobre a importância de considerar os conhecimentos produzidos pelos professores, a partir de suas experiências in loco. Para sustentar esse argumento, o autor defende a necessidade de "[...] ir diretamente aos lugares onde os profissionais do ensino trabalham, para ver como eles pensam e falam, como trabalham na sala de aula, como transformam programas escolares para torná-los efetivos, como interagem com os pais dos alunos, com seus colegas etc."

A partir desse entendimento, podemos inferir que esta busca pelo reconhecimento da legitimidade de suas práticas não advém de um conhecimento 
raso e desinteressado, mas resulta de uma sensibilidade que se constrói na dinâmica das relações com os alunos, das trocas de saberes e experiências com seus pares, da ampliação dos conhecimentos da própria área disciplinar em que ensinam e pelo aprofundamento dos conhecimentos sobre o processo de aprendizagem. Esses conhecimentos, por sua vez, estão pautados por uma consciência política, posto que suas ações são dotadas de uma intencionalidade que se volta à obtenção dos objetivos que pretendem alcançar. Por tudo isso, esse movimento reflete o desejo desses profissionais em serem reconhecidos e, assim, demarcarem um campo de conhecimento e uma área de atuação que lhes é própria.

Para um percentual de 38,5\% dos professores entrevistados, as experiências decorrentes de seus processos de formação foram menos impactantes, dado o argumento de que, embora reconheçam a sua relevância, esta estaria mais relacionada ao campo da regulamentação de um estatuto profissional, ou seja, das formalidades legais relativas à concessão da licença para atuarem.

Quanto à construção de um conhecimento próprio sobre a área em que atuam, compreendem que esse é forjado, sobretudo, por intermédio das experiências práticas que, de acordo com suas percepções, é de fato o que os prepara para o ofício. Essa ideia é devidamente ilustrada pela narrativa a seguir "[...] $\mathrm{Na}$ verdade, mais do que minha formação, minha experiência tem influenciado muito mais minhas práticas e minhas buscas por novas abordagens" (P:19).

No tocante à realização de cursos de formação continuada, no período da pesquisa, 8,2\% dos professores declararam estarem frequentando cursos de Especialização. O P:78 relatou participar de formações que abordam temas, como: Combate ao bullying na escola e Sexualidade entre os adolescentes; e o P:17 informou fazer curso de Especialização na área de Literatura. Os demais professores que compõem esse percentual, não informaram quais cursos estariam fazendo.

Vale destacar que, conforme apresentado no perfil dos profissionais, 59\% dos professores têm curso de Especialização e 13\% o curso de Mestrado que, somados aos 8,2\% em processo de formação em cursos de Especialização, mostram 
que cerca de 80,2\% desses sujeitos participaram ou participam de cursos de formação continuada.

No tocante à formação em serviço, 93\% dos professores pesquisados disseram considerar muito importante ações de formação continuada, destacando que se ressentem pela ausência de um plano ou projeto voltado à formação permanente, que assegurasse reais condições para que pudessem participar desses momentos, tendo em vista que a conciliação entre essas atividades e o trabalho que realizam nas escolas, torna-se difícil de pôr em prática, sobretudo para aqueles que têm 40 ou mais horas de trabalho semanal que, neste estudo, representam um percentual de 90, 2\% dos participantes. Essa percepção é representada pela fala da P-12 (2018), ao declarar que:

[...] Eu e a maioria dos meus colegas consideramos muito importantes esses momentos, mas na prática é muito complicado, porque é difícil conciliarmos, trabalhamos no mínimo os dois turnos, temos família, filhos e temos que dividir nossa atenção, como não há de fato uma ação que garanta termos esses momentos dentro da nossa carga horária de trabalho, acaba que dificilmente temos essa oportunidade.

Esse relato ilustra as limitações encontradas por muitos profissionais para realizarem atividades de caráter formativo. Cumpre destacar, que esta configura uma realidade comum para a maior parte dos professores que compõem a rede pública de ensino, no estado do Pará.

A oferta de atividades de formação desconectadas com as necessidades manifestadas por alunos e professores foi mencionada por um percentual de $57 \%$ dos entrevistados, argumentando que, embora as ações de formação tenham sempre um lado positivo, os resultados seriam muito melhores se elas estivessem em sintonia com a realidade e os desafios que a escola e os professores enfrentam, no tocante às dificuldades relativas ao ensino e a aprendizagem e outras questões que transversalizam o contexto escolar, como: indisciplina, violência, combate ao uso de drogas, dentre outros problemas mencionados por muitos dos entrevistados. O relato do P- 21 (2018) expõe essa percepção:

Eu confesso que para mim a formação é algo muito importante, mas na minha carreira, já estou há 18 anos na rede estadual, já cheguei a participar de formações que não atendiam a realidade 
da escola, as necessidades dos professores. Eu acredito que é muito válido, mas que precisa também estar de acordo com o que precisamos, se não acaba sendo uma iniciativa da escola que é boa, é claro, mas que no fim não vai ter os resultados que se espera.

Em relação as ações de formação em serviço, muitos são os desafios encontrados em diversos contextos escolares. Sobre esta perspectiva, Gatti e Barreto (2009) advertem que a falta de sintonia entre as expectativas, as necessidades da comunidade escolar e os cursos ofertados é uma queixa recorrente no tocante ao tema da formação de professores em serviço. Segundo as autoras, mesmo quando os efeitos sobre a prática são positivos, persistem ainda os problemas relativos a descontinuidade dos programas de formação, que dificultam chegar a resultados realmente exitosos. Sobre esse aspecto, Gatti e Barreto (2009, p. 221) complementam,

A formação continuada é organizada com pouca sintonia com as necessidades e dificuldades dos professores e da escola; os professores não participam das decisões acerca dos processos de formação aos quais são submetidos; os formadores não têm conhecimento dos contextos escolares e dos professores que estão a formar [...] falta melhor cumprimento da legislação que assegura ao professor direito a formação continuada.

Esse enunciado levanta uma série de questões que constituem desafios que, há tempos, requerem ações mais efetivas, isto porque, em que pese à recorrência dessa denúncia por estudos e pesquisas, desenvolvidas em realidades e contextos educacionais diversos, tais problemas mostram-se cada vez mais persistentes.

A análise do conjunto de questões, mencionadas pelos professores, evidencia a urgência de um planejamento efetivo e direcionado a resolver esses problemas, a medida em que estes se configuram como impasses com implicações prejudiciais às ações que visam a qualificação e o desenvolvimento profissional, aspectos indispensáveis ao aprimoramento da prática pedagógica docente e, de modo mais amplo, ao fortalecimento da categoria e da própria profissão.

\section{Aprimoramento teórico e prático continuado}

O aprimoramento teórico e prático continuado surge nas narrativas desses professores correlacionado a ideia de progresso, no sentido de desenvolvimento 
profissional que pode ser atestado, na medida em que essa evolução, em termos de qualidade do trabalho que realizam, tem efeitos aparentes nas aprendizagens de seus alunos. Nesse contexto, a temática aprimoramento teórico e prático continuado, assume imagens e sentidos que se relacionam a elementos semânticos, como: superação, reconhecimento, potencialidades de crescimento, desenvolvimento pessoal e profissional que se refletem no desejo de continuarem evoluindo. Essas evocações comparecem nas narrativas de $89,7 \%$, dos professores entrevistados.

Ao se auto avaliarem em relação a como conduzem sua prática pedagógica docente, $86,1 \%$ desses professores, o fizeram de forma positiva, sobretudo, ao considerarem os problemas nevrálgicos que afetam diretamente a carreira do magistério, referenciados nessas narrativas como descaso com a educação e ausência de políticas públicas que, de fato, impactem no desenvolvimento e qualidade do ensino. Essa percepção é ilustrada pelo relato da P:27: “[...] Eu me vejo como profissional da área de educaşão completamente atuante, responsável e comprometida com o processo de ensino e aprendizagem”. Esse relato é complementado pela percepção da P:04, ao declarar “[...] vejo a minha prática como a melhor possivel, tendo em vista as condições de trabalho que nos são oferecidas na escola pública (nenhuma!), posso dizerer que não fui "engolida pelo sistema" como muitos afirmam que foram".

As ideias representadas pelos relatos do P:10 e do P:15 são emblemáticas quanto a percepção do papel que 64,7\% dos docentes entrevistados compreendem que desempenham no processo de formação de seus alunos, na medida em que, para além de trabalharem os conteúdos de ensino de suas respectivas componentes curriculares, partilham a crença de também contribuírem de modo significativo com o processo de formação mais amplo desses estudantes, conforme pode ser observado nas narrativas a seguir:

[...] Tenho a convicção de contribuir em muito para a educação do município. Também acredito que estimulei muitos alunos a permanecerem na escola, a continuarem seus estudos e até mesmo a ingressarem na profissão e também a se tornarem pessoas melhores (P:10, 2018).

[...] Me avalio com uma carreira acadêmica muito boa, pois, procurei me munir de conhecimentos na área de ensino e aprendizagem. Tenho uma formação em Licenciatura em Letras e também sou Especialista em Gestão e Docência do Nível Superior. Enfim, não parei no 
tempo, sempre que há uma nova oportunidade para me capacitar e melhorar a minha prática (P:15, 2018).

Essa postura se inscreve no conceito de profissionalidade que compreende também esse movimento de busca contínua pelo aperfeiçoamento e desenvolvimento profissional e pessoal. A própria formação continuada ou a busca por ela, a ânsia que o professor tem por ampliar seus conhecimentos, por crescer, aprimorar-se e ser reconhecido por isso entre os pares e pela sociedade, implica em um movimento de dentro para fora, é uma busca, uma procura porque depende, em grande medida, da mobilização desses profissionais para criarem as condições necessárias para alcançarem seus objetivos (PAULA JÚNIOR, 2012).

Esse movimento de mobilização pela melhoria das condições de trabalho requer um forte senso de profissionalidade, porquanto esta palavra pode ser representada

[...] como desenvolvimento sistemático da profissão, fundamentada na prática e na mobilização/atualização de conhecimentos especializados e no aperfeiçoamento das competências para a atividade profissional. É um processo não apenas de racionalização de conhecimentos, e sim de crescimento na perspectiva do desenvolvimento profissional (RAMALHO; NUNEZ; GAUTHIER, 2003, p. 50).

Esse movimento de busca pela ampliação e ressignificação de seus saberes como um caminho para o desenvolvimento profissional, por sua vez, concorre para a construção das bases da profissionalização, visto que ao reivindicarem e se articularem na luta pela garantia de condições para o aperfeiçoamento de suas práticas, os professores constroem, enquanto profissionais, uma nova perspectiva sobre a profissão, para si, para seus pares e, de modo mais abrangente, para a própria sociedade.

Gatti (2013) complementa esse entendimento ao afirmar que a profissionalização implica a obtenção de um espaço autônomo, próprio à sua profissionalidade, com valor claramente reconhecido pela sociedade. Em outras palavras, não há consistência em uma profissionalização desprovida de uma base sólida de conhecimentos e formas efetivas de ação. 
Para esses professores, o acesso às condições de desenvolvimento profissional tem ressonâncias muito positivas no aprimoramento da prática pedagógica docente, que repercutem de modo global para a melhoria do processo de ensino e aprendizagem, constituindo estímulos que podem, inclusive, motivar o ingresso e a permanência na profissão.

\section{Considerações finais}

No processo de análise das representações sociais desses professores, identificamos uma tendência em reconhecer a importância da dimensão teórica dos processos formativos pelos quais passaram, ao longo de sua profissionalização. Entretanto, constatamos que estes são unânimes em referendar o conhecimento advindo das experiências práticas, vivenciadas no cotidiano do trabalho, como elemento imprescindível a compreensão do que é, de fato, ser professor. Em suas perspectivas é a partir da dimensão pragmática do ofício que se pode compreender seus matizes, bem como desenvolver e aprimorar os conhecimentos e habilidades que os habilite a gerir da melhor maneira o processo de aprendizagem de seus alunos.

Assim, o estudo das representações sociais de professores da Educação Básica do município de Belém-PA, sobre a inter-relação entre formação profissional e prática pedagógica docente, indica que as objetivações e as ancoragens que constituem as suas representações fundamentam-se no consenso de que a formação profissional deve também ter em consideração, os conhecimentos produzidos a partir das experiências práticas provenientes do exercício da profissão. Esse movimento é essencial à construção de um saber próprio e específico da área, bem como está relacionado a constituição de uma identidade e fortalecimento do estatuto profissional.

As RS desses profissionais mostram que a formação, a experiência e a prática docente são aspectos que se retroalimentam, contribuindo para a ampliação e a consolidação dos conhecimentos e saberes essenciais ao ofício, bem como para o alcance das condições necessárias para o desenvolvimento da carreira. 
Nesse sentindo, consideramos que é preciso melhorar as ações voltadas à formação profissional, aspecto que reafirma a necessidade de reestruturação dos modelos formativos direcionados à qualificação de docentes, tanto em suas bases teórico- práticas e epistemológicas, quanto na forma de organização e oferta, de modo a favorecer reais condições de participação desses profissionais nessas atividades.

As imagens e os sentidos, construídos em torno do aprimoramento teórico e prático continuado, revelam que embora não encontrem as condições ideais para participarem de atividades de qualificação e melhoria de suas práticas, tanto em razão das limitações que as formações disponibilizadas apresentam, quanto pelas limitações relacionadas às próprias condições de trabalho e carreira em que se inserem, esses profissionais têm buscado alternativas para aperfeiçoarem as suas práticas.

Nesse contexto, apesar de apontarem para as dificuldades encontradas, os professores representam-se como profissionais que resistem a um cenário desfavorável a um projeto de educação democrática e inclusiva, reconhecendo-se como sujeitos atuantes e comprometidos com a formação cidadã, científica e técnica de seus alunos.

\section{Referências}

ABRIC, J. C. (org). Pratiques sociales et représentations. Paris: Presses Universitaires de France, 1994.

ARRUDA, A. Subjetividade, mudança e representações sociais. In: FURTADO, O.; REY, F. L. G. Por uma epistemologia da subjetividade: um debate entre a Teoria SócioHistórica e a Teoria das Representações Sociais. 2. ed. São Paulo: Casa do Psicólogo, 2002. p. 65-75.

BRAUN, V.; CLARKE, V. Using thematic analysis in psychology. Qualitative Research inPsychology, v. 3, n . 2, p. 77-101, 2006. Disponível em: https://www.academia.edu/29999208/Tradu\%C3\%A7\%C3\%A3o_do_artigo_Usin g_thematic_analysis_in_psychology_. Acesso em: 31 maio 2020.

DELORS, J. Educação: um tesouro a descobrir. São Paulo: Cortez; Brasília: MEC/ UNESCO, 1998. 
FIDALGO, F.; MACHADO, L. (ed.). Dicionário da educaşão profissional. Belo Horizonte: NETE-UFMG, 2000.

GAMBOA, S. S. Pesquisa em educação: métodos e epistemologias. 2. ed. Chapecó: Argos, 2012.

GATTI, B. A. Educação, escola e formação de professores: políticas e impasses. Educar em Revista, Curitiba, n. 50, p. 51-67, out./dez. 2013. Disponível em: https://www.scielo.br/pdf/er/n50/n50a05.pdf. Acesso em: 31 maio 2020.

GATTI, B. A.; BARRETO, E. S. de S. Professores do Brasil: impasses e desafios. Brasília: UNESCO/MEC, 2009.

GOMES, A. A. A Construção da Identidade Profissional do Professor: uma análise de egressos do curso de Pedagogia. In: CONGRESSO PORTUGUÊS DE SOCIOLOGIA, 6., 2008. Anais... Lisboa: Associação Portuguesa de Sociologia, 2002. (Tema: Mundos sociais: saberes e práticas). Disponível em: https://dialnet.unirioja.es/servlet/ articulo?codigo=4554585. Acesso em: 31 maio 2020 .

INSTITUTO NACIONAL DE ESTUDOS E PESQUISAS EDUCACIONAIS ANÍSIO TEIXEIRA (INEP). Censo escolar. resultados e resumos. Brasília: MEC, 2019. Disponível em: http://portal.inep.gov.br/web/guest/resultados-e-resumos. Acesso em: 1 jun. 2020.

JODELET, D. Representações sociais: um domínio em expansão. In: JODELET, D. (org.). As representações sociais. Rio de Janeiro: Vozes, 2001.

MONTEIRO, A. R. Profissão docente: profissionalização e autorregulação. São Paulo: Cortez, 2015.

MOSCOVICI, S. A representaşão social da psicanálise. Rio de Janeiro: Zahar, 1978.

NASCIMENTO, I. P.; RODRIGUES, S. E. C. Os fatores que determinam a permanência na docência e as implicações no trabalho e nos desafios da contemporaneidade: um estudo sobre os professores de ensino médio. Educação $e$ Pesquisa, São Paulo, v. 44, 1-16, 2018.

NEVES. J. d'A. de. V.; NASCIMENTO, I. P. As representações sociais dos professores das séries iniciais sobre o ser professor no atual contexto históricosocial e as implicações para sua identidade docente. In: CONGRESSO NACIONAL DE EDUCAÇÃO - EDUCERE, 11., 2013. Anais eletrônicos... Curitiba: Pontifícia Universidade Católica do Paraná, 2013. p. 8772-8779. Disponível em: https://educere.bruc.com.br/ANAIS2013/pdf/9079_6065.pdf. Acesso em: 31 maio 2020. 
PAULA JÚNIOR, F. V. de. Profissionalidade, profissionalização, profissionalismo e formação docente. Scientia, v. 1, n. 1, p. 1-191, jun./nov. 2012. Disponível em: http://www.faculdade.flucianofeijao.com.br/site_novo/scientia/servico/pdfs/outr os_arti gos/Revista_area_AFIM_01.pdf. Acesso em: 31 maio 2020.

RAMALHO, B.L.; NUÑEZ, I.B.; GAUTHIER, C. Formar o professor, profissionalizar o ensino. Porto Alegre: Sulina, 2003

ROUQUETTE, M. L. Sur la connaissance des masses: essai de psychologie politique. Grenoble: Presses universitaires de Grenoble, 1994.

SEVERINO, A. J. Metodologia do trabalho cientifico. São Paulo: Cortez, 2007.

TARDIF, M. Saberes profissionais dos professores e conhecimentos universitários: elementos para uma epistemologia da prática profissional dos professores e suas consequências em relação à formação para o magistério. Revista Brasileira de Educação, Rio de Janeiro, v. 3, n. 13, p. 5-24, jan./abr. 2000.

TRIVIÑOS, A. N. Introdução à pesquisa em ciências sociais: a pesquisa qualitativa em educação. São Paulo: Atlas, 1987.

WILLE, R. B.; FERREIRA, M. O. V. Desenvolvimento profissional ao longo do tempo e no trabalho: quais possibilidades? In: LOPES, A. et al (ed.). Trabalho docente e formação: políticas, práticas e investigação: pontes para a mudança. Porto: CIIE, 2014. p. 5198-5208. v. 4. Disponível em: <https://www.fpce.up.pt/trabalhodocenteformacao/ assets/TrabalhoDocenteEFormacao_Vol_IV.pdf>. Acesso em: 31 maio 2020.

RECEBIDO: 01/06/2020 APROVADO: 13/08/2020

RECEIVED: 06/01/2020 APPROVED: 08/13/2020

RECIBIDO: 01/06/2020 APROBADO: $13 / 08 / 2020$ 